\title{
EVALUATING BIOCHEMICAL INTERNET RESOURCES
}

\author{
Lima, R.M., Xavier-Filho, J. and Fernandes, K.V.S. \\ Universidade Estadual do Norte Fluminense, CBB, LQFPP, Campos dos \\ Goytacazes, R.J. Centro Federal de Educação Tecnológica de Campos, \\ Universidade da Tecnologia e do Trabalho, CEFET/Campos, Campos dos \\ Goytacazes, R.J.
}

Many people fail to properly evaluate INTERNET information. This is often due to a lack of understanding of the issues, by responsible authorities, and, more specifically, a lack of understanding of the structure and modis operandi of the INTERNET tool. The aim of this project was to analyze biochemical issues available in WEB pages, evaluating contents quality, coverage, accuracy, authority and currency. Twenty three sites were analyzed for their contents, presence of bibliographical references, authorship, titles responsibility and adequacy to target public. The great majority (95\%) did not mention bibliographic references and target public. Less than half divulged names and/or graduation status of responsibles. Some sites contained critical conceptual errors, such as: oxygen is essential for anaerobic respiration; presence of $\mathrm{H}_{2} \mathrm{O}$ in photosynthesis dark phase; yeast is a pluricellular fungal; the overall equation of photosynthesis with errors; $\mathrm{NADH}_{2}$ instead $\mathrm{NAD}^{+}$; etc. None of the analyzed sites was thus considered excellent. Although the use of the internet is expanding rapidly on college campuses, little is known about students usage; how they perceive the reality of internet information and how successful they are in searching through it. Our data strenghthen the need for rigorous evaluation concerning to educational research of biochemical themes on the WEB.

Supported by: UENF and Cefet/Campos. 